\title{
DETERMINATION OF FOUR ARSENIC SPECIES IN ALGAE BY HIGH-PERFORMANCE LIQUID CHROMATOGRAPHY COUPLED WITH HYDRIDE GENERATION ATOMIC FLUORESCENCE SPECTROMETRY
}

\author{
Sun Peng ${ }^{\mathrm{a}, \mathrm{b}, *,(1)}$, Gao Yuling ${ }^{\mathrm{a}, \mathrm{b}}$, Zhang Xiaolin ${ }^{\mathrm{c}}$ and Yan Rui ${ }^{\mathrm{a}, \mathrm{b}}$ \\ ${ }^{a}$ Center of Management of Laboratory Equipment, Heilongjiang Bayi Agricultural University, 163319 - Daqing, China \\ ${ }^{\mathrm{b}}$ Agricultural Products and Procesed Products Supervision and Testing Center, Ministry of Agriculture, 163319 - Daqing, China \\ 'Technology Center, Dalian Customs District,116000 - Dalian, China
}

Recebido em 03/04/2020; aceito em 13/05/2020; publicado na web em 22/06/2020

\begin{abstract}
A rapid method has been developed for the determination of silver arsenite As(III), dimethylated arsenic DMA, monomethylated arsenic MMA, and arsenate $\mathrm{As}(\mathrm{V})$ in algae sample using liquid chromatography coupled with hydride generation atomic fluorescence spectrometry (LC-HG-AFS). Types, flow rate and $\mathrm{pH}$ of mobile phase were optimized. Under the optimal conditions, there were good linear relationships in the range of $0-200 \mu \mathrm{g} \mathrm{L}^{-1}$ with correlation coefficients larger than 0.9995 . The limits of detection and quantification of As(III), DMA, MMA, and As(V) were 0.005- $0.010 \mathrm{mg} \mathrm{kg}^{-1}$ and $0.019-0.034 \mathrm{mg} \mathrm{kg}^{-1}$, respectively. The recoveries at three spiked levels of $0.02,0.5$ and $1.0 \mathrm{mg} \mathrm{kg}^{-1}$ were in the range of 93-105\% with relative standard deviations (RSD, $\left.n=6\right)$ of $3.6 \%-6.2 \%$. The proposed method was successfully applied in the determinaton of four arsenic species in algae sample. The developed method is simple, higher precision, stable data collection, and shorter separation time, and could be applied in the speciation and study of arsenic species in algae.
\end{abstract}

Keywords: algae; arsenic species; LC-HG-AFS

\section{INTRODUCTION}

Trace amounts of arsenic can be detected in soil, water, animals, and plants, as well as human bodies due to the ingestion of food and drinking water. Studies have shown that moderate amounts of arsenic have a positive effect on human growth and development because it contributes to the synthesis of hemoglobin. However, excessive intake of arsenic and its inorganic compounds can cause poisoning and cancer. ${ }^{1,2}$

The presented arsenic speciation includes methyl arsenate (MMA), dimethyl arsenate (DMA), arsenobetaine (AsB), and inorganic arsenic ( As (III) and As (V) ).${ }^{3,4}$ Arsenic toxicity is related to both its total amount and also its chemical form. For example, mono-arsenic is non-toxic, but arsenic compounds have varying degrees of toxicity, pentavalent arsenic is less toxic than trivalent arsenic, and organic arsenic is less toxic than inorganic arsenic. Arsenic compounds become enriched in algae due to their ingestion from the surrounding environment and are then converted into a variety of fat-soluble and water-soluble compounds. Therefore, it is importance to detect arsenic species in algae for protecting the health and safety of consumers.,

Current methods for detecting inorganic arsenic in food include atomic fluorescence spectroscopy (AFS) ${ }^{7-9}$ liquid chromatographyatomic fluorescence spectroscopy (LC-AFS), ${ }^{10-13}$ and liquid chromatography-inductively coupled plasma mass spectrometry (LC-ICP-MS). ${ }^{14-16}$ AFS is widely used but is often used only to determine the total amount of inorganic arsenic. LC-ICP-MS is highly sensitive, but its equipment and operating requirements are expensive, resulting in a high detection cost. LC-AFS can be used for morphological analysis and as a hydrogenation atomic fluorescent spectrometer and has a simple operation and flexible conversion. ${ }^{17}$ In order to ensure that the form of arsenic does not change during the extraction process, different extractants can be selected according to

*e-mail: byndsunpeng@163.com the actual situation of sample matrix. ${ }^{18-22}$ In this paper, LC-HG-AFS was used to analyze the amounts of As(III), As(V), MMA, and DMA in algae samples. The algae samples were extracted by dilute nitric acid, four arsenic species in extracting solution were separated by HPLC. After separation, the four arsenic species were subjected to potassium borohydride hydrolysis to produce gaseous arsenic compounds that were measured by atomic fluorescence spectroscopy. The liquid chromatography conditions were optimized, and four arsenic species showed excellent separation, enabling the quantitative analysis of arsenic species in algae samples. The developed method can be used for reference for the determination of arsenic speciations in foods, and provided technical support for carrying out safety assessment.

\section{EXPERIMENTAL}

\section{Instruments}

LC-HG-AFS was performed using a 9560 instrument (Beijing Haiguang Instrument Co., Ltd, China). An incubator with a temperature control system from Shanghai Precision and Scientific Instrument Corporation was used. Samples were treated with a Z36 HK centrifuge (HERMLE Co., Germany), IKA T25 Homogenizer (EIKA Equipment Co., Germany). Samples were weighed using an ML204 electronic analytical balance (Mettler-Toledo Co., USA), and a Vortex-Genie 2 Vortex Agitator (Scientific Industries, Inc., USA).

\section{Materials}

Kelp, Porphyra, and Undaria pinnatifida were purchased from a wholesale market in Daqing, China.

As(III) standard solution (GBW08666, $1.011 \mu \mathrm{mol} \mathrm{g} \mathrm{g}^{-1}$ ), As(V) standard solution (GBW8667, $0.233 \mu \mathrm{mol} \mathrm{g}^{-1}$ ), MMA standard

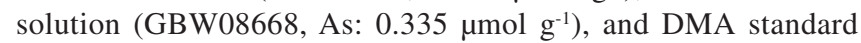
solution (GBW08669, $0.706 \mu \mathrm{mol} \mathrm{\textrm {g } ^ { - 1 }}$ ) were purchased from the National Institute of Metrology of China. 
Ammonium dihydrogen phosphate, potassium borohydride, and sodium hydroxide were purchased from Tianjin Kemio Chemical Reagent Co., Ltd. Nitric acid and hydrochloric acid were purchased from Fisher Scientific, USA. A 0.22- $\mu$ m microporous membrane was obtained from Dikma Technologies (Beijing, China). The test water is ultrapure water. The chromatographic column (Hamilton PRP-X100 $4.1 \mathrm{~mm} \times 250 \mathrm{~mm}, 10 \mu \mathrm{m}$ ) was purchased from Beijing Haiguang Instrument Co., Ltd.

\section{Sample pre-treatment}

$1.000 \mathrm{~g}$ of Kelp (Porphyra or Undaria pinnatifida) were added into a $50 \mathrm{~mL}$ PTFE centrifuge tube, and then $10 \mathrm{~mL}$ of $0.15 \mathrm{~mol} \mathrm{~L}^{-1}$ nitric acid was were successively added and placed overnight. Afterward, the $50 \mathrm{~mL}$ PTFE tube were dipped in a constant-temperature bath at $90{ }^{\circ} \mathrm{C}$, then taken out and shaken for 1 min every $0.5 \mathrm{~h}, 2$ hours later, and then cooled down to the room temperature. The $50 \mathrm{~mL}$ centrifuge tube was centrifuged for $15 \mathrm{~min}$ at $10,000 \mathrm{rpm}$. The upper $5 \mathrm{~mL}$ supernatant was further transferred into a $15 \mathrm{~mL}$ PTFE centrifuge tube, and then $5 \mathrm{~mL}$ hexane was added and shaken for $1 \mathrm{~min}$, centrifuged for $15 \mathrm{~min}$ at $10,000 \mathrm{rpm}$, and the upper hexane layer was discarded. This process was repeated once, and the subnatant was filtered by a $0.22 \mu \mathrm{m}$ organic membrane before LC-AFS analysis. The blank and spiked sample were conducted in the same way.

\section{Standard solution preparation}

The standard solution containing the above four arsenic speciation was diluted with $0.15 \mathrm{~mol} \mathrm{~L}^{-1}$ nitric acid into a series of standard working solutions of 2, 5, 10, 50, 100, 150 and $200 \mu \mathrm{g} \mathrm{L}^{-1}$. A standard curve was constructed from the concentration of the four arsenic speciation in the series of standard working solutions and the corresponding peak area.

\section{Instrumental conditions}

\section{Liquid chromatography conditions}

Chromatographic column: Hamilton PRP-X100 4.1 mm x 250 mm, $10 \mu \mathrm{m}$, Beijing Haiguang Instrument Co., Ltd; $150 \mu \mathrm{L}$ injection volume, $1.0 \mathrm{~mL} \mathrm{~min}^{-1}$ mobile phase flow rate; mobile phase: disodium hydrogen phosphate-potassium monohydrogen phosphate $(\mathrm{pH}=6.0)$, using isocratic elution.

\section{Atomic fluorescence conditions}

Negative high voltage: $300 \mathrm{~V}$; As lamp current of $80 \mathrm{~mA}$; atomizer height of $9 \mathrm{~mm}$, carrier gas flow rate of $300 \mathrm{~mL} \mathrm{~min}^{-1}$; shield gas flow rate: $900 \mathrm{~mL} \mathrm{~min}^{-1} .10 \%(\mathrm{~V} / \mathrm{V})$ hydrochloric acid as carrier liquid, mixed solution of $15 \mathrm{~g} \mathrm{~L}^{-1}$ potassium borohydride and $0.5 \%(\mathrm{~m} / \mathrm{m})$ potassium hydroxide as the pre-reducing agent and the hydriding agent.

$\mathrm{KBH}_{4}+3 \mathrm{H}_{2} \mathrm{O}+\mathrm{H}^{+}=\mathrm{H}_{3} \mathrm{BO}_{3}+\mathrm{K}^{+}+8 \mathrm{H}^{*}+\mathrm{E}^{m+}=E H_{n}+\mathrm{H}_{2}$

where $E^{m+}, E H_{n}$ are signals out from the analytic element and gaseous hydrides.

\section{RESULTS AND DISCUSSION}

\section{Optimized liquid chromatography conditions}

Choice of Mobile Phase: This is why bubbles in the mobile phase can interfere with separation, cause baseline drift, peak changes, and deviations in detection, so the mobile phase was ultrasonically degassed for 30 minutes. The effects of two different flow rates relative to chromatographic peaks and the response strength of $\mathrm{NH}_{4} \mathrm{H}_{2} \mathrm{PO}_{4}-\mathrm{NaH}_{2} \mathrm{PO}_{4}$ and $\mathrm{KH}_{2} \mathrm{PO}_{4}-\mathrm{NaH}_{2} \mathrm{PO}_{4}$ were compared. When using $\mathrm{KH}_{2} \mathrm{PO}_{4}-\mathrm{NaH}_{2} \mathrm{PO}_{4}$ as the mobile phase, the baseline was stable, the peak symmetry was good, and the target compound obtained a higher response value, so $\mathrm{KH}_{2} \mathrm{PO}_{4}-\mathrm{NaH}_{2} \mathrm{PO}_{4}$ was selected as the mobile phase.

Choice of Mobile Phase pH: A PRP-X100 anion exchange column was used, which has a wide $\mathrm{pH}$ range from 1 to 13 . The $\mathrm{pH}$ value of the mobile phase was very important for separation of target compound. Samples were extracted with $0.15 \mathrm{~mol} \mathrm{~L}^{-1}$ nitric acid, and the $\mathrm{pH}$ of the extracted sample solution was around 2 . The effect of the mobile phase $\mathrm{pH}(3,4,5,6,7,8)$ on the analysis results was optimized. The optimal $\mathrm{pH}$ was adjusted 6 .

Choice of Flow Rate: The flow rate of mobile phase have significant influences on the symmetry of arsenic species signal peak as well as the recovery of four arsenic species and then finally affects the accuracy of final result. Flow rates of 0.6, 0.8, 1.0, 1.2, and $1.4 \mathrm{~mL} \mathrm{~min}^{-1}$ were used to examine their effect on the peak shape and response intensity of the four arsenic speciation. The relationship between the flow rate of mobile phase and the symmetry of arsenic speciation signal peak $\left(\mathrm{KH}_{2} \mathrm{PO}_{4}-\mathrm{NaH}_{2} \mathrm{PO}_{4}, \mathrm{pH}=6.0\right.$, isocratic elution $)$ are shown in Figure 1. As can be observed, the optimal flow rate was

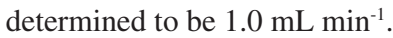

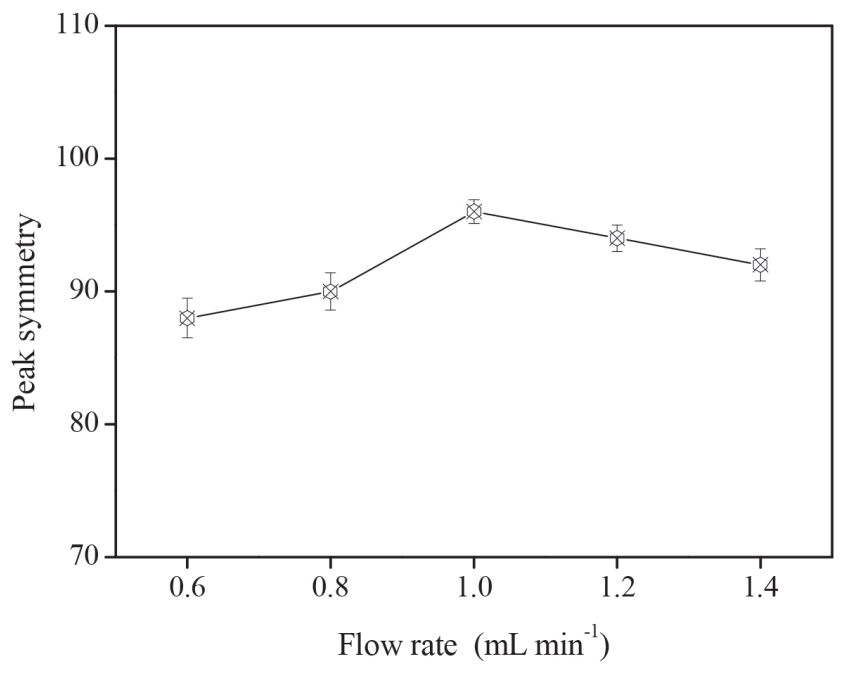

Figure 1. Effect of fiow rate of mobile phase on the peak symmetry ( $\mathrm{KH}_{2} \mathrm{PO}_{4}-\mathrm{NaH}_{2} \mathrm{PO}_{4}$ mobile phase, isocratic elution, $\mathrm{pH}=6$, injection volume $150 \mu L)$

\section{Linear relationship and detection limit}

The standard stock solution of four arsenic speciation was diluted using $0.15 \mathrm{~mol} \mathrm{~L}^{-1}$ nitric acid solution. The standard working solution with concentrations of $0,2,5,8,10,15,30,50,100,150$, and $200 \mu \mathrm{g} \mathrm{L}^{-1}$ were obtained. Using the optimal conditions, the concentration corresponding to the arsenic response value was used to obtain the standard equation with good linear relationship and low detection limit. (Table 1).

\section{Precision and accuracy of the method}

To estimate the precision and accuracy of the proposed method, kelp samples was analyzed with spiked concentration levels of 0.02 , 0.5 and $1.0 \mathrm{mg} \mathrm{kg}^{-1}$, respectively. Under the optimized conditions 
Table 1. Linear range, calibration equations, r, LOD, LOQ and RSD of the method

\begin{tabular}{|c|c|c|c|c|c|}
\hline Compound & Regression equation & Linear range $\left(\mu \mathrm{g} \mathrm{L}^{-1}\right)$ & $\mathrm{r}$ & $\operatorname{LOD}\left(\mathrm{mg} \mathrm{kg}^{-1}\right)$ & LOQ $\left(\mathrm{mg} \mathrm{kg}^{-1}\right)$ \\
\hline $\mathrm{As}(\mathrm{III})$ & $y=38928 x-86723$ & $0 \sim 200$ & 0.9998 & 0.005 & 0.019 \\
\hline DMA & $y=26554 x+278145$ & $1 \sim 150$ & 0.9999 & 0.010 & 0.034 \\
\hline MMA & $y=29619 x+179086$ & $1 \sim 150$ & 0.9996 & 0.006 & 0.021 \\
\hline $\mathrm{As}(\mathrm{V})$ & $y=20081 x+43053$ & $2 \sim 200$ & 0.9995 & 0.009 & 0.031 \\
\hline
\end{tabular}

established above, the recovery and relative standard deviation of arsenic were calculated and listed in Table 2 . The recovery rate was measured to be between $93-105 \%$, and the precision was between $3.6 \%$ and $6.2 \%$. This shows that this method can be applied to analyze and detect arsenic in algae samples.

Table 2. Recovery and precision of As(III), DMA, MMA, As(V) in kelp samples

\begin{tabular}{|c|c|c|c|c|}
\hline Compound & $\begin{array}{c}\text { Background } \\
\left(\mathrm{mg} \mathrm{kg}^{-1}\right)\end{array}$ & $\begin{array}{c}\text { Spiked (mg } \\
\left.\mathrm{kg}^{-1}\right)\end{array}$ & Recovery (\%) & $\operatorname{RSD}(\%)$ \\
\hline & & 0.02 & 96 & 5.6 \\
\hline \multirow[t]{3}{*}{ As(III) } & 0.078 & 0.5 & 97 & 4.2 \\
\hline & & 1.0 & 100 & 3.6 \\
\hline & & 0.02 & 103 & 4.8 \\
\hline \multirow[t]{3}{*}{ DMA } & 0.000 & 0.5 & 99 & 4.9 \\
\hline & & 1.0 & 93 & 5.6 \\
\hline & & 0.02 & 97 & 6.2 \\
\hline \multirow[t]{3}{*}{ MMA } & 0.000 & 0.5 & 105 & 3.8 \\
\hline & & 1.0 & 98 & 5.2 \\
\hline & & 0.02 & 95 & 4.0 \\
\hline \multirow[t]{2}{*}{$\mathrm{As}(\mathrm{V})$} & 0.058 & 0.5 & 93 & 5.6 \\
\hline & & 1.0 & 102 & 3.8 \\
\hline
\end{tabular}

\section{Determination of arsenic in algae samples}

After demonstrating the feasibility of this method, algae samples were purchased from a wholesale market for processing. $150 \mu \mathrm{L}$ supernatants from 4 kelp samples were absorbed, and the four arsenic speciation content was measured and analyzed using the LC-HG-AFS method (Figure 2). The content of trivalent arsenic and pentavalent

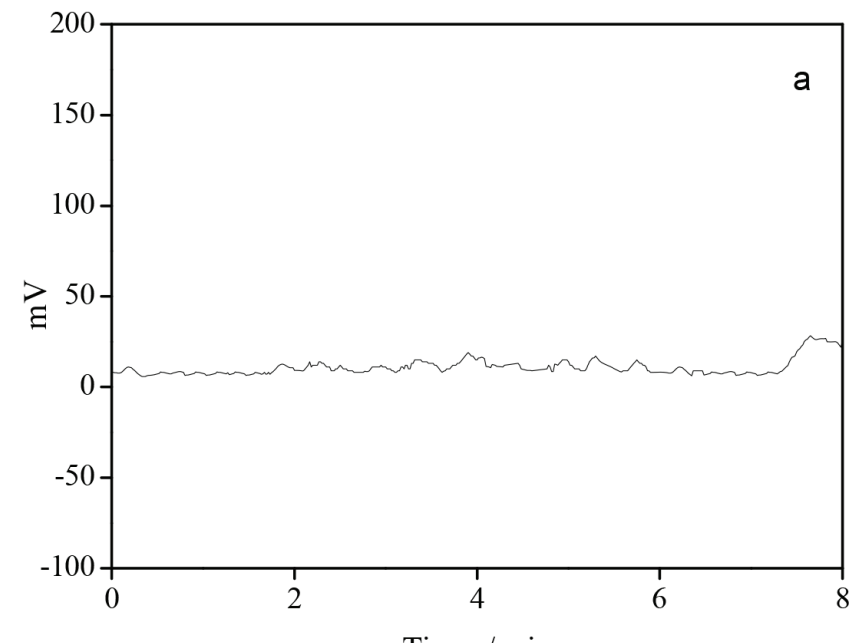

Time / min

Figure 2. HPLC-HG-AFS chromatograms of (A) blank sample, (B) spiked sample with the four arsenic species $\left(\mathrm{KH}_{2} \mathrm{PO}_{4}-\mathrm{NaH}_{2} \mathrm{PO}_{4}\right.$ mobile phase, isocratic elution, $\mathrm{pH}=6$, injection volume $150 \mu \mathrm{L}$, fiow rate $1.0 \mathrm{~mL} \mathrm{\textrm {min } ^ { - 1 } )}$ arsenic in the kelp samples were obtained and the levels of arsenic speciation in the algae samples were calculated (Table 3).

Table 3. Analysis of As(III), DMA, MMA, As(V) in algae samples $\mathrm{mg} \mathrm{kg}^{-1}$

\begin{tabular}{lccc}
\hline Compound & Kelp & Porphyra & $\begin{array}{c}\text { Undaria } \\
\text { pinnatifida }\end{array}$ \\
\hline As(III) & 0.147 & 0.181 & 0.134 \\
As(V) & 0.107 & 0.096 & 0.079 \\
DMA & ND & ND & ND \\
MMA & ND & ND & 0.027 \\
\hline
\end{tabular}

\section{Comparison of the proposed method with others}

Listed in Table 4 are the experimental results of HPLC-ICP-MS, ${ }^{23,24}$ HPLC-HG-AFS, ${ }^{25,26}$ and the proposed method. In comparison with those reported methods for the separation and determination of arsenic species, the proposed method has some advantages in higher precision, more accuracy, and shorter separation time.

To evidence the performance of the present method applicable to the detection of four arsenic species in algae samples were analyzed with the proposed procedure. After the nitric acid extraction as described above in the section of sample preparation, these samples were subjected to LC-HG-AFS analyses under the optimized liquid chromatography and atomic fluorescence conditions. The four arsenic speciation were separated and determined within 6 minutes. This method has a simple operation, in higher precision, stable data collection, and shorter separation time, and can be applied to analyze and study arsenic species in algae samples.

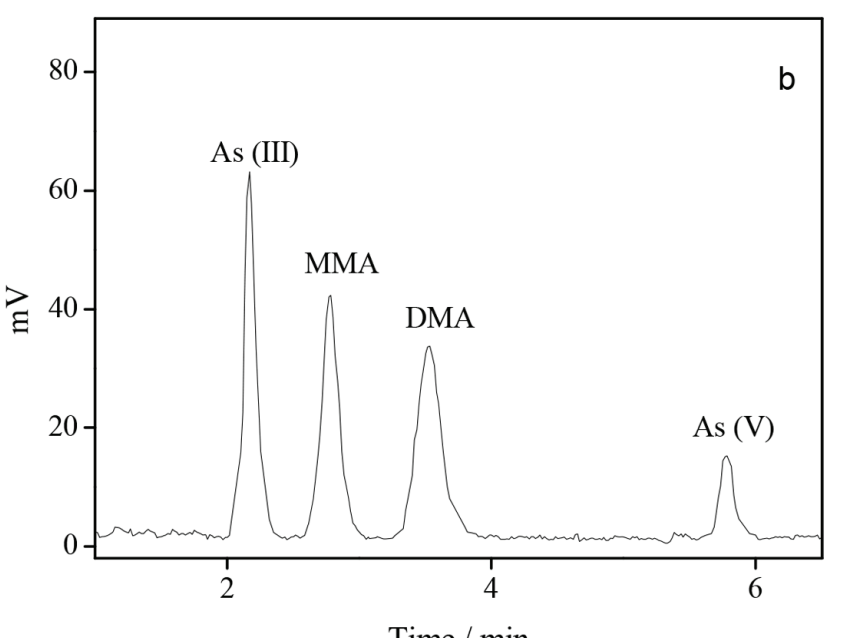

Time $/ \min$

\section{CONCLUSION}


Table 4. Comparison of developed method and other methods

\begin{tabular}{|c|c|c|c|c|c|c|}
\hline Analytes & Matrix & Recovery (\%) & $\mathrm{LOD}\left(\mu \mathrm{g} \mathrm{kg^{-1 }}\right)$ & Precision (RSD\%) & Separation time (min) & References \\
\hline HPLC-ICP-MS & herbal tea leaves & $75-108$ & 7.6-11 & $<9.0$ & 5 & 23 \\
\hline HPLC-ICP-MS & fish & $91-106$ & $0.11-0.59$ & $<7.6$ & 7 & 24 \\
\hline HPLC-HG-AFS & blood & 81-109 & $0.08-0.27$ & $<12.5$ & 6 & 25 \\
\hline HPLC-HG-AFS & antarcic krill & 89-108 & 10 & $<14$ & 10 & 26 \\
\hline HPLC-HG-AFS & algae & $93-105$ & 5 & $<6.2$ & 6 & in this study \\
\hline
\end{tabular}

\section{ACKNOWLEDGMENTS}

This work was supported by Heilongjiang Bayi Agricultural University Support Program for San Heng San Zong (No. ZRCQC201910, No. PTJH201905)

\section{REFERENCES}

1. Vlezd, D.; Montoro, R.; J. Food Protect. 1998, 61, 1240.

2. Quinaia, P. S.; Rollemberg, E., M. C.; J. Braz. Chem. Soc. 1997, 8, 349.

3. El-Hadri, F.; Morales-Rubio, A.; Guardia, M. D. L.; Food Chem. 2007, 105, 1195

4. Ito, K.; Palmer, C. D.; Corns, W. T.; Parsons, P. J.; J. Anal. Atom Spectrom. 2010, 25, 822.

5. Khan, N.; Ryu, K. Y.; Choi, J. Y.; Nho, E. Ye.; Habte, G.; Choi, H.; Kim, M. H.; Park, K. S.; Kim, K. S.; Food Chem. 2015, 169, 464.

6. Quináia, P. S.; Rollemberg, E., M. Carmo.; J. Braz. Chem. Soc.2001, 12, 37.

7. Zhang, Y.; Manuel, M.; Kolev, S. D.; Talanta 2018, 189, 786.

8. Moreno, E.; Cámara, C.; Corns, W. T.; Bryce, D.W.; Stockwell, P. B.; J. Autom. Method Manag. 2014, 22, 33.

9. Li, S.; Wang, M.; Zhong, Y.; Zhong, Z.; Yang, B.; Spectrochim. Acta B 2015, 111, 74 .

10. Guo, M. H.; Li, J.; Fan, S. J.; Liu, W. S.; Wang, B.; Gao, C. L.; Zhou, J.; Hai, X.; J. Pharm. Biomed. Anal. 2019, 171, 212.

11. Guo, M. H.; Wang, W. J.; Hai, X.; Zhou, J.; J. Pharm. Biomed. Anal. 2017, $145,356$.
12. Wei, C. J.; Liu, J. X.; Talanta 2007, 73, 540.

13. Jesus, J. P.; Suárez, C. A.; Ferreira; R. J., M.; Giné, F.; Talanta 2011, 85, 1364.

14. Andrea, B. R. K.; Meharg, A. A; Charnock, M. J.; Feldmann, J.; Anal. Bioanal. Chem. 2008, 390, 1739.

15. Ritsema, R.; Dukan, L.; Navarro, T. R. I. ; Leeuwen, W. V. ; Lebret, E.; Appl. Organomet. Chem., 1998, 12, 591.

16. Akter, K. F.; Chen, Z.; Smith, L.; Davey, D.; Naidu, R.; Talanta 2005, $68,0$.

17. Narukawa, T.; Chiba, K.; Sinaviwat, S.; Feldmann, J.; J. Chromatogr. A, 2017, 1479, 129.

18. Zhang, W. H.; Qi, Y. H.; Qin D. Y.;Liu, J. X.; Mao, X. F.; Chen, G. Y.; Wei, C.; Qian, Y. Z.; Talanta 2017, 170, 152.

19. Orkun, A.; Gokce, T.; Food Chem. 2019, 290, 10.

20. Najafi, A., Hashemi, M.; Microchem. J. 2019, 150:104102.

21. Zhou, J.; Deng, D. Y.; Su, Y. Y.; Lv, Y.; Microchem. J. 2019, 146, 359.

22. Moreda-Piñeiro, A.; Moreda-Piñeiro, J.; Herbello-Hermelo, P.; BermejoBarrera, P.; Muniategui-Lorenzo, S.; López-Mahía, P.; Prada-Rodríguez, D.; J. Chromatogr. A, 2011, 1218, 6970.

23. Milani, R. F.; Lima de Paiva, E.; Peron, L. I.; Morgano, M. A.; Cadore, S.; LWT, 2018, 98, 606.

24. Zhao, F.; Liu, Y. M.; Zhang, X. Q.; Dong, R.; Yu, W.J.; Liu, Y.F .; Guo, Z. M.; Liang, X. M.; Zhu, J. H.; J.Chromatogr. A 2018, 1573, 48.

25. Guo, M. H.; Wang, W. J.; Hai, X.; J. Pharmaceut. Biomed. 2017, 145, 356.

26. Liu, S. H.; Zhang, H. Y.; Lou, X. Y.; Kong, C.; Wang, Y. Shi, Y. F.; Huang, X. Y.; Shen, X. S.; J. Instrumental Anal. 2019, 38, 1085. 